Revista de Derecho

de la Pontificia Universidad Católica de Valparaíso

53 (segundo semestre de 2019)

[pp. 177-197]

\title{
DOS PROYECCIONES DE LA TEORÍA DEL DELITO EN LA IMPOSICIÓN DE MEDIDAS CAUTELARES PERSONALES EN EL PROCESO PENAL CHILENO
}

\begin{abstract}
[Two projections of the Theory of Crime in the imposition of Personal Precautionary measures in the chilean Criminal Process]
\end{abstract}

\section{Guillermo Oliver Calderón*}

\begin{abstract}
RESUMEN
El principal objetivo de este artículo es determinar el significado y alcance de la voz "delito" en la regulación de la detención por flagrancia y de la prisión preventiva, en el Código Procesal Penal chileno. El método usado es, básicamente, sistemático, analizando varias disposiciones del sistema procesal penal de este país. El principal resultado es la atribución a dicha palabra de un significado y alcance distinto, según se trate de la detención por flagrancia o de la prisión preventiva.
\end{abstract}

\section{Palabras clave}

Derecho procesal penal - delito - detención - flagrancia - prisión preventiva - medidas cautelares.
Abstract

The main objective of this article is to determine the meaning and scope of the word "crime" in the regulation of detention for flagrante delicto and pretrial detention in the Chilean Code of Criminal Procedure. The method used is basically systematic, analyzing various provisions of the criminal procedure system of this country. The main result is the attribution to that word of a different meaning and scope, depending on whether it is a question of detention for flagrante delicto or pretrial detention.

\section{KEYWORDS}

Criminal Procedure Law- crime arrest - flagrante delicto - pretrial detention - precautionary measures.

* Doctor en Derecho por la Universidad de Barcelona. Profesor de Derecho penal y Derecho procesal penal en la Pontificia Universidad Católica de Valparaíso. Dirección electrónica: guillermo.oliver@pucv.cl. Dirección postal: Avenida Brasil, 2950, Valparaíso, Chile.

El autor agradece a la ayudante de investigación del Departamento de Derecho Penal y Derecho Procesal Penal de la Pontificia Universidad Católica de Valparaíso, Michelle López Arancibia, y al abogado asesor de la Fiscal Regional del Ministerio Público de Valparaíso, Daniel Polanco Valdés, por su colaboración en la búsqueda de jurisprudencia pertinente para este trabajo. 
Recibido el 2 de septiembre de 2019 y Aprobado el 27 de noviembre de 2019.

\section{INTRODUCCIÓN}

A pesar de que autores clásicos del Derecho penal, como Feuerbach, en su Lehrbuch des gemeinen in Deutschland geltenden Peinlichen Rechts (Gießen, 1801) y Carrara, en su Programma del corso di diritto criminale (Pisa, 1864), trataban en sus obras no solo materias penales, sino también procesales penales ${ }^{1}$, lo cierto es que, tal vez como consecuencia del proceso de codificación, que separó las normas tipificadoras de delitos y penas de las normas procedimentales, reuniendo aquéllas en Códigos penales y éstas en Códigos procesales, a partir de dicho proceso ha sido usual que la ciencia del Derecho penal y la ciencia del Derecho procesal penal se ignoren mutuamente ${ }^{2}$. Esto ha hecho que algunos contenidos de la teoría del delito, que influenciada fuertemente por la dogmática alemana ha alcanzado un muy alto nivel de elaboración, no hayan recibido aplicación práctica, y que en los operadores jurídicos sea notoria una comprensión del Derecho procesal penal puramente ritual o procedimental.

Tal indiferencia mutua es más evidente en aquellas Facultades de Derecho en las que, tras la separación de las asignaturas de Derecho penal y Derecho procesal penal, los profesores encargados de impartir el ramo de Derecho penal no abordan aspectos procesales penales, y quienes enseñan Derecho procesal penal, usualmente, después de haber impartido ellos mismos los cursos de Derecho procesal civil, no tratan contenidos penales ${ }^{3}{ }^{4}$. Esto último ha propiciado la dedicación de varios procesalistas

${ }^{1}$ En este sentido, Zaffaroni, Eugenio Raúl - Alagia, Alejandro - Slokar, Alejandro, Derecho Penal. Parte General (2a edición, Ediar, Buenos Aires, 2003), p. 166.

${ }^{2}$ Ragués i VAllès, Ramon, Derecho penal sustantivo y Derecho procesal penal: hacia una visión integrada, en Hurtado Pozo, José (dir.), Anuario de Derecho Penal. La reforma del proceso penal peruano (Lima, Pontificia Universidad Católica del Perú, Fondo editorial-Universidad de Friburgo Suiza, 2004), pp. 129-130.

${ }^{3}$ Ragués i VAllès, cit. (n. 2), p. 130, quien, aludiendo al caso español, recalca el hecho de que, en su Manual de Derecho Penal, José Antón Oneca afirma que el estudio del juicio dentro de los tratados de Derecho penal "debe considerarse deficiencia técnica de épocas ya superadas".

${ }^{4}$ Esta es, por cierto, la tónica en el actual panorama académico chileno. Sin embargo, en los últimos años se ha percibido un cambio en algunas universidades de este país, probablemente debido a la Reforma Procesal Penal del año 2000. Por ejemplo, la Pontificia Universidad Católica de Valparaíso, en el año 2007, sustrajo la asignatura de Derecho procesal penal del Departamento de Derecho Procesal y la adscribió al nuevo Departamento de Derecho Penal y Derecho Procesal Penal. Desde entonces, en dicha casa de estudios, en general, los cursos de Derecho procesal 
a elaborar una suerte de teoría general del proceso aplicable tanto al proceso civil como al penal, lo que dada la pretensión de universalidad y uniformidad en sus conceptos, ha tendido a oscurecer varios problemas propios del proceso penal 5 .

En las últimas décadas, un sector de la doctrina penal ha comenzado a llamar la atención acerca de la necesidad de cambiar este estado de $\operatorname{cosas}^{6}$. Sin llegar, en general, al extremo de echar por tierra la distinción

penal son impartidos por profesores que también enseñan Derecho penal. Asimismo, en la Universidad Austral de Chile, desde hace muy pocos años, en general, la asignatura de Derecho procesal penal es impartida por profesores de Derecho penal. En una situación intermedia parece hallarse la Universidad Diego Portales, en la cual, al igual que la Pontificia Universidad Católica de Valparaíso, las asignaturas de Derecho penal y Derecho procesal penal se encuentran adscritas a un mismo Departamento, pero a diferencia de ella, quienes imparten Derecho procesal penal no enseñan Derecho penal, y viceversa.

${ }^{5}$ Véase Maier, Julio B. J., Derecho Procesal Penal (Buenos Aires, Ad-Hoc, 2016), I, p. 136-137: "Siguiendo la tradición de los países de habla hispana, nuestra organización académica y científica, si de ella se puede hablar hoy en día, ha dejado el Derecho procesal penal en manos de juristas casi siempre ligados al Derecho procesal civil. De allí el auge de la teoría uniforme del Derecho procesal en nuestro medio [...], que procura una explicación única de los fenómenos principales de todos los derechos procesales (teoría general única del proceso), al precio de la decoloración política de ambas disciplinas y de la escasa claridad de las soluciones propuestas. [...] En busca de una síntesis, arquitectónicamente bella, pero inútil por inexistencia de similitudes políticas entre una y otra rama del Derecho procesal, se reduce la posibilidad de alcanzar soluciones sencillas y prácticas. [...] Los penalistas, por su parte, salvo honrosas excepciones [...], han abandonado el Derecho procesal penal a las manos de los expertos en Derecho procesal, con resultados cuestionables" (las cursivas en el original). Asimismo, Roxin, Claus, Derecho Procesal Penal (traducción de la $25^{\text {a }}$ edición alemana de Gabriela E. Córdoba y Daniel R. Pastor, Buenos Aires, Editores del Puerto, 2000), p. 6, quien señala que "la utilidad de tal punto de vista ha sido hasta ahora muy reducida".

${ }^{6}$ En la doctrina alemana, paradigmáticamente, Freund, Georg, Sobre la función legitimadora de la idea de fin en el sistema integral del Derecho penal, en WOLTER, Jürgen - Freund, Georg (eds.), El sistema integral del Derecho penal. Delito, determinación de la pena y proceso penal (Madrid, Marcial Pons, 2004), pp. 91-128, quien propone diseñar un "sistema integral del Derecho penal", en el que no sólo esté "el Derecho penal sustantivo y el Derecho de la determinación de la pena, sino también el Derecho procesal penal como auténtico campo de aplicación de los dos anteriores" (p. 93) (las cursivas en el original). "Desde este enfoque lo que suele denominarse sistema del delito es simplemente un subsistema del más amplio sistema integral del Derecho penal, que se orienta a la aplicación del Derecho penal y abarca, por tanto, al Derecho de la determinación de la pena y al Derecho procesal” (p. 95) (el destacado también en el original). En la doctrina chilena, recientemente, VERA SÁNCHEZ, Juan Sebastián, Sobre la relación del Derecho penal con el Derecho procesal 
entre lo sustantivo y lo procesal -aunque importantes voces se han dejado oír, cuestionando la corrección de dicha separación ${ }^{7}-$, se ha destacado la conveniencia de que, por un lado, la teoría del delito se oriente al proceso penal y, por otro, la comprensión de las etapas e instituciones del proceso penal guarde mayor relación con los elementos del concepto de delito. Este breve trabajo apunta al último de dichos objetivos. Teniendo a la vista la normativa sobre las medidas cautelares personales en el Código Procesal Penal chileno (en adelante, CPP), se pretende esclarecer el modo en que los elementos de la definición general de delito se proyectan en algunos aspectos de tal regulación. Con dicha finalidad, tras un muy sucinto examen de los requisitos generales de las medidas cautelares personales en el CPP, se analizan algunos aspectos de la teoría del delito en la regulación que este cuerpo normativo efectúa de la detención por delito flagrante ${ }^{8}$ y de la prisión preventiva.

\section{REQUisitos GENERALES DE LAS MEDIDAS CAUTELARES PERSONALES EN EL} CPP

Conforme a lo que señala la doctrina chilena acerca de la regulación procesal penal de este país, salvo ciertas particularidades que presenta la citación y algunas formas de detención, en general, para que un tribunal pueda decretar una medida cautelar personal debe constatar la presencia

penal, en Revista Chilena de Derecho 44 (2017), 3, pp. 831-855, quien sugiere asumir una comprensión sincrónica o de retroalimentación entre el Derecho penal y el Derecho procesal penal.

7 Por ejemplo, Jakовs, Günther, Derecho Penal. Parte General. Fundamentos y teoría de la imputación (traducción de la 2a edición alemana de Joaquín Cuello Contreras y José Luis Serrano González de Murillo, Barcelona, Marcial Pons, 1997), p. 411: "La delimitación entre Derecho sustantivo y procesal no sólo se discute en los casos concretos, sino también a nivel de principio". También PASTOR, Daniel R., Acerca de presupuestos e impedimentos procesales y sus tendencias actuales (2001), ahora, en el MISMO, Tensiones. ¿Derechos fundamentales o persecución penal sin limites? (Buenos Aires, Editores del Puerto, 2004), p. 57: "En realidad, derecho penal y derecho procesal penal no pueden ser separados y no sólo en este terreno de frontera, sino en todo el ámbito de actuación de ambas ramas del orden jurídico penal”.

${ }^{8} \mathrm{El}$ tratamiento que en este trabajo se hace de la detención por flagrancia delictiva como una especie de medida cautelar, no pretende rebatir a la doctrina que ha criticado esta forma de comprender la detención por delito flagrante. Solo obedece a que en el CPP es regulada dentro de un título cuyo epígrafe reza así: "Medidas cautelares personales". Criticando dicha forma de comprender la detención por flagrancia, puede verse LOPES JR., Aury, O novo regime jurídico da prisão processual, liberdade provisória e medidas cautelares diversas (Río de Janeiro, Editora Lumen Juris, 2011), pp. 30-32. 
de dos requisitos, en cuya nomenclatura se deja ver con claridad una aproximación teórica elaborada a propósito de la tutela cautelar en el proceso civil':

a) Fumus boni iuris ("humo de buen derecho"). Esto significa la probabilidad de que el hecho punible haya tenido lugar y que el imputado haya intervenido en él. Dado que esta expresión latina se corresponde más con el proceso civil, en el proceso penal se prefiere denominar a este requisito como fumus delicti commissi $1^{10}$.

b) Periculum in mora ("peligro en la demora"). Se conoce también este presupuesto de aplicación con el nombre "necesidad de cautela", lo que significa la probabilidad de que el imputado, durante el proceso penal, pueda frustrar los fines del procedimiento. Dicha expresión latina también se corresponde más con el proceso civil; en el proceso penal es preferible la expresión periculum libertatis ${ }^{11}$.

De estos dos requisitos, es indudablemente el primero el más importante para los fines de este trabajo. La circunstancia de que para imponer una medida cautelar sea necesario un cierto estándar de convicción acerca de que el hecho delictivo haya tenido lugar y de que en él haya cabido al imputado una intervención delictiva, permite introducir en el análisis de esta materia procesal penal algunas consideraciones propias de la teoría del delito.

\section{Aspectos de TeOrÍA DEL Delito EN LA REGUlaCión DE LA DETENCiÓN POR DELITO FLAGRANTE}

\section{Generalidades sobre detención por flagrancia delictiva}

De acuerdo con lo previsto en el artículo 83 letra b) CPP, corresponde a los funcionarios de Carabineros de Chile y de la Policía de Investigaciones de Chile "practicar la detención en los casos de flagrancia, conforme a la ley".

${ }^{9}$ Por todos, en el sentido de lo que a continuación se indica en el texto, véase Marín González, Juan Carlos, Las medidas cautelares personales en el nuevo Código Procesal Penal chileno, en Revista de Estudios de la Justicia, Universidad de Chile 1 (2002), pp. 13-16.

${ }^{10}$ Así, Nieva Fenoll, Jordi, Fundamentos de Derecho Procesal Penal (Madrid, Buenos Aires, Montevideo, Edisofer; B de F, 2012), p. 160. Por su parte, Pujadas Tortosa, Virginia, Teoría general de medidas cautelares penales. Peligrosidad del imputado y protección del proceso (Madrid, Marcial Pons, 2008), pp. 111-112, propone sustituir la expresión fumus boni iuris por el vocablo "imputación”.

${ }^{11}$ En este sentido, Nieva Fenoll, Jordi, Derecho Procesal III. Proceso penal (Madrid, Marcial Pons, 2017), pp. 255-256, quien, en todo caso, niega que se trate de un auténtico presupuesto de adopción de una medida cautelar, afirmando que más bien es una descripción de la situación cautelable. 
La detención por este motivo constituye un deber de la policía (art. 129 inc. $2^{\circ} \mathrm{CPP}$ ) y procede cuando ésta sorprende a una persona in fraganti en la comisión de un delito ${ }^{12}$. Como es sabido, la voz flagrante proviene del verbo flagrar (del latín flagrare), que, conforme al diccionario de la lengua española de la RAE, significa arder o resplandecer como fuego o llama. Esto resulta ilustrativo y permite entender los requisitos que la doctrina suele exigir en la flagrancia ${ }^{13}$ :

a) Coetaneidad o inmediatez: Esto implica que la persona debe ser sorprendida, cometiendo el delito o en el momento mismo en que lo acaba de cometer.

b) Ostensibilidad: Esto quiere decir que el hecho delictivo debe ser patente o manifiesto, o sea, que se desprenda de su sola observación, sin que sea necesario realizar ningún tipo de indagación. La ostensibilidad, entonces, se opone a la existencia de meras sospechas o indicios.

Sabido es que las hipótesis de flagrancia son mencionadas en el artículo $130 \mathrm{CPP}$, cuyo encabezado establece que "se entenderá que se encuentra en situación de flagrancia" una persona en las seis hipótesis que la disposición prevé. Esta frase del legislador obedece a que, en estricto rigor, no todos los casos a los que alude el precepto corresponden al concepto de flagrancia propiamente tal o flagrancia real (sorprender a una persona in fraganti en la comisión de un delito), el cual estaría recogido en las letras a) y b) de la disposición. Las hipótesis de las restantes letras corresponden, más bien, a un concepto amplio de flagrancia (flagrancia ficta o virtual), ya que en todas ellas ha transcurrido un tiempo desde la comisión del hecho. Por eso se ha dicho que del encabezado del artículo $130 \mathrm{CPP}$ "se puede desprender un primer cuestionamiento constitucional a la regulación legal; alguien contra quien no se ha librado una orden de detención judicial puede ser detenido sin que exista propiamente una flagrancia" 14 .

${ }^{12}$ Los siguientes párrafos relativos a la detención por delito flagrante han sido extraídos, en ocasiones en forma literal, de Oliver Calderón, Guillermo, Facultades autónomas de la policía en el sistema procesal penal chileno, en Revista de Derecho de la Pontificia Universidad Católica de Valparaíso 51 (2018), pp. 40-43.

${ }^{13}$ Por todos, en el sentido de lo que se señala enseguida en el texto, Maturana Miquel, Cristián - Montero López, Raúl, Derecho Procesal Penal (3 ${ }^{a}$ edición, Librotecnia, Santiago, 2017), I, p. 637; Romero Muza, Rubén, Control de identidad y detención. Doctrina y jurisprudencia (2a edición, Librotecnia, Santiago, 2007), pp. 87-88.

${ }^{14}$ VitAR CÁCERES, Jorge, La detención por flagrancia y la modificación de la Ley 20.253, ahora, en Fuentes Maureira, Claudio (coord.), Diez años de la reforma procesal penal en Chile (Santiago, Ediciones Universidad Diego Portales, 2011), p. 561. 
Las situaciones de flagrancia que la ley prevé son las siguientes:

a) El que actualmente se encontrare cometiendo el delito.

b) El que acabare de cometerlo. Esta hipótesis ha dado lugar a una discusión: mientras unos entienden que al momento de ser detenido el imputado debe hallarse en el lugar de comisión del delito ${ }^{15}$, otros aceptan que pueda encontrarse en cualquier lugar ${ }^{16}$. Según mi opinión, es la primera tesis la correcta. Con independencia de que es difícil que el sujeto se halle en un lugar distinto al de la ejecución del delito si de verdad acaba de cometerlo, una interpretación sistemática permite afirmar que el imputado debe ser encontrado en el lugar de comisión del hecho. En efecto, en la siguiente letra de este artículo (letra c) la ley se refiere a quien huye del lugar de ejecución del delito, lo que sugiere que en la hipótesis de la letra b) el sujeto se halla aún en ese lugar. Por lo demás, solo así podría afirmarse que en esta letra se recoge una auténtica hipótesis de flagrancia propiamente tal o real; si el imputado se encontrara en un lugar distinto al de la comisión del hecho, no se cumpliría el requisito de la ostensibilidad. Por último, el artículo $5^{\circ}$ inciso segundo CPP obliga a interpretar restrictivamente este precepto.

c) El que huyere del lugar de comisión del delito y fuere designado por el ofendido u otra persona como autor o cómplice. A diferencia de las hipótesis previstas en las letras siguientes, en las cuales la ley formula una exigencia temporal, en esta situación no lo hace, lo que a mi juicio puede interpretarse como la posibilidad de que la persecución se prolongue en el tiempo, siempre que no se suspenda y que el imputado no se ponga fuera del alcance de quien le persigue ${ }^{17}$.

d) El que, en un tiempo inmediato a la perpetración de un delito, fuere encontrado con objetos procedentes de aquél o con señales, en si mismo o en sus vestidos, que permitieren sospechar su participación en él, o con las armas o instrumentos que hubieren sido empleados para cometerlo.

e) El que las víctimas de un delito que reclamen auxilio, o testigos presenciales, señalaren como autor o cómplice de un delito que se hubiere cometido en un tiempo inmediato.

f) El que aparezca en un registro audiovisual cometiendo un crimen o

${ }^{15}$ Así, Durán Fuica, Rodrigo, Medidas cautelares personales en el proceso penal (3a edición, Santiago, Librotecnia, 2011), p. 178; Maturana - Montero, cit. (n. 13), p. 635 .

${ }^{16}$ En este sentido, Aguilar Aranela, Cristian, Medidas cautelares personales y reales en el proceso penal (Santiago, Librotecnia, 2014), p. 45.

${ }^{17}$ Similar, Cerda SAn MarTín, Rodrigo, Manual del sistema de justicia penal (2a edición, Santiago, Librotecnia, 2010), I, p. 348, quien alude a esta idea con la frase "continuidad de la persecución”. 
simple delito al cual la policía tenga acceso en un tiempo inmediato.

Para los efectos de lo establecido en las letras d), e) y f) se entenderá por tiempo inmediato todo aquel que transcurra entre la comisión del hecho y la captura del imputado, siempre que no hubieren transcurrido más de doce horas.

En el caso contemplado en la letra $\mathrm{f}$ ), obviamente, las doce horas deben contarse desde la ejecución del hecho que ha quedado grabado en el registro, no desde que la policía tiene acceso al mismo ${ }^{18}$. Además, si bien la exigencia de que se trate de un registro audiovisual es fácil de cumplir en muchos casos, tales como las filmaciones desde teléfonos celulares, no lo es en muchos otros, como sucede, por ejemplo, con las cámaras de vigilancia, las cuales, en general, sólo permiten obtener registros visuales ${ }^{19}$.

Un examen rápido de esta disposición permite concluir que la regulación de la flagrancia delictiva no cumple los requisitos doctrinales, ya que sólo las hipótesis de las letras a) y b) los satisfacen. Por lo que respecta a la coetaneidad o inmediatez, no puede sostenerse que esté presente cuando han transcurrido cerca de doce horas desde la comisión del hecho; claramente, es sólo una ficción del legislador. Y en cuanto a la ostensibilidad, ésta también puede ser puesta en tela de juicio, pues en los casos de las letras c), d) y e) no es necesario que el delito sea evidente para quien practica la detención.

Resulta especialmente criticable la asimilación a la flagrancia que el legislador hace en las letras d), e) y f), al entender por tiempo inmediato todo aquel que no supere las doce horas. Como sostiene Falcone, "que la Constitución disponga, específicamente, que sin existir una orden, la detención sólo cabe en virtud de delito flagrante, es una garantía de la libertad personal. El legislador no puede crear causas de detención y determinar, arbitrariamente, que ellas constituyen situaciones de flagrancia, en desmedro del derecho fundamental" ${ }^{\prime 20}$.

\section{Consideraciones de teoría del delito}

Del examen de la normativa sobre la detención por flagrancia delictiva se desprende que el más importante aspecto propio de la teoría del delito

${ }^{18}$ Lo destaca Cerda San Martín, Rodrigo, Segunda Ley de Agenda Corta Antidelincuencia. Comentarios desde la práctica jurisdiccional (Santiago, Librotecnia, 2016), p. 86.

${ }^{19}$ En este sentido, Sánchez Rodríguez, Sergio, Para entender la agenda corta antidelincuencia. Ley 20.931 (Santiago, Editorial Metropolitana, 2016), p. 61.

${ }^{20}$ Falcone Salas, Diego, Concepto y sistematización de la detención ilegal en el proceso penal chileno, en Revista de Derecho, Pontificia Universidad Católica de Valparaíso 38 (2012), pp. 467-468. 
que se proyecta en aquélla, es el concepto de delito que subyace a tal regulación.

Como es sabido, la doctrina penal suele entender el delito, en general, como un hecho típicamente antijurídico y culpablemente ejecutado, añadiéndose en ocasiones la exigencia de que sea punible ${ }^{21}$. Pues bien, el alcance del vocablo "delito", para efectos de la detención por flagrancia delictiva, dependerá de la determinación de los elementos del concepto doctrinal de delito que se consideren pertinentes para ello. Básicamente, la pregunta central es la de si para detener en hipótesis de flagrancia basta con la constatación de que se está ante un hecho formalmente típico, o si es necesario, además, que se trate de un comportamiento antijurídico y, eventualmente, culpable y punible. En lo que se me alcanza, este punto, en general, no ha sido objeto de análisis en la doctrina nacional ${ }^{22}$. Lo mismo sucede en la jurisprudencia de nuestros tribunales ${ }^{23}$.

A pesar de que puede afirmarse que la tipicidad no es un elemento verdaderamente independiente de la antijuridicidad penal ${ }^{24}$, para efectos de este trabajo conviene examinar la tipicidad separadamente de la antijuridicidad. Ya la formulación de la pregunta que se acaba de plantear

${ }^{21}$ Cfr. Mir Puig, Santiago, Derecho Penal. Parte General (10 edición, Barcelona, Reppertor, 2016), p. 148, quien, con todo, asume una postura que entiende el delito como un hecho penalmente antijurídico y personalmente imputable.

${ }^{22}$ Excepcionalmente, Cisterna Pino, Adolfo, La detención por flagrancia en el nuevo proceso penal. Doctrina y jurisprudencia (Santiago, Librotecnia, 2004), p. 59, sí ha examinado este punto, exigiendo para la detención por delito flagrante solo la tipicidad del hecho.

En la doctrina extranjera tampoco es objeto de mucho estudio el punto relativo al significado que quepa atribuir a la voz "delito" en la regulación de la detención por flagrancia de las distintas legislaciones procesales penales. En España, véase DE Hoyos Sancho, Montserrat, La detención por delito (Pamplona, Aranzadi, 1998), p. 79, n. 32, quien, aludiendo a las hipótesis de flagrancia del artículo 490 de la Ley de Enjuiciamiento Criminal, entiende por dicho vocablo una referencia a un comportamiento típicamente antijurídico. En el mismo sentido, QUERALT JiMÉNEZ, Joan, La detención preprocesal preventiva: previsiones constitucionales y legales, ahora, en Álvarez Álvarez, Gregorio (dir.), Detención policial y "habeas corpus" (Madrid, Consejo General del Poder Judicial, 2010), p. 63.

${ }^{23}$ Sin embargo, algunos pronunciamientos existen, predominando en ellos la idea de que, para detener por delito flagrante, basta con constatar la tipicidad del hecho. En este sentido, véanse las sentencias de la Corte Suprema, de 13 de julio de 2016, en causa rol No 32863-2016; de la Corte de Apelaciones de San Miguel, de 6 de marzo de 2017, en causa rol No 394-2017, y de la Corte de Apelaciones de Valdivia, de 13 de noviembre de 2014, en causa rol $N^{\circ}$ 651-2014. Exigiendo tipicidad, antijuridicidad y culpabilidad, véase la sentencia de la Corte de Apelaciones de Concepción, de 2 de febrero de 2018, en causa rol N²9-2018.

${ }^{24}$ Así, Mir PUig, cit. (n. 21), p. 169. 
sugiere que resulta posible analizar ambos elementos del delito en forma separada.

Aun a riesgo de descuidar parte importante de su contenido como elementos del delito, por simplificar en demasía su descripción, puede decirse que la tipicidad de un comportamiento consiste en su correspondencia con un tipo penal; la antijuridicidad, en la ausencia de causas de justificación ${ }^{25}$.

Pues bien, la revisión de la normativa sobre la detención por flagrancia delictiva sugiere que cuando ella utiliza el vocablo "delito", en general, lo hace para aludir a un hecho que es típico. En otras palabras, de dicha regulación parece desprenderse que para detener a alguien por delito flagrante basta la constatación de la tipicidad del hecho ejecutado por esa persona, sin que sea necesario que, además, se compruebe, en el acto de la detención, la antijuridicidad, la culpabilidad y la punibilidad del comportamiento. Es esto lo que se colige del artículo $138 \mathrm{CPP}$, que señala que "la detención del que se encontrare en los casos previstos en el párrafo segundo del número $6^{\circ}$ del artículo 10 del Código Penal se hará efectiva en su residencia”. Como es sabido, esta última disposición del Código Penal (en adelante, CP) establece dos supuestos de presunción simplemente legal de la concurrencia de los requisitos de la legítima defensa. De la lectura de ambas disposiciones fluye que en tales supuestos la detención resulta procedente a pesar de que el hecho típico pueda estar justificado por la legítima defensa, por lo que parece claro que lo único que debe saltar a la vista para detener en hipótesis de flagrancia delictiva es la tipicidad del hecho.

Téngase presente, en apoyo de la misma idea, que la policía tiene un deber (general) ${ }^{26}$ de detener a quien sorprenda en delito flagrante y que ésta tiene que evaluar en el mismo momento de constatación del hecho su carácter delictivo. Así las cosas, no sería razonable exigirle la comprobación, en ese instante, de elementos del delito adicionales a la tipicidad, varios de las cuales podrían permanecer en la incertidumbre, incluso, hasta la sentencia definitiva. Por lo demás, una indagación destinada a establecer esos otros elementos del delito es contraria a la idea de flagrancia ${ }^{27}$.

${ }^{25}$ Por todos, Cerezo Mir, José, Derecho Penal. Parte General (Buenos AiresMontevideo, B de F, 2008), p. 311.

${ }^{26}$ Como es sabido, cuando se trata de faltas o de delitos que la ley no sanciona con penas privativas ni restrictivas de libertad, salvo ciertas excepciones, la flagrancia delictiva no permite detener, sino solo citar al imputado a la presencia del fiscal, previa comprobación de su domicilio (arts. 124 y $134 \mathrm{CPP}$ ).

${ }^{27}$ En este sentido, Cisterna Pino, cit. (n. 22), pp. 59-60, quien añade que "basta con que la ostensibilidad del hecho permita concluir que es típico, pero no es 
Con todo, considero necesario efectuar en este punto la siguiente matización. De acuerdo con lo que se lleva dicho, en términos generales, bastará con la constatación de la tipicidad para detener por flagrancia delictiva. No lo impedirá la presencia de dudas acerca del carácter antijurídico del hecho típico, como cuando existen antecedentes que sugieren una legítima defensa o un estado de necesidad justificante, porque no es la policía, sino el tribunal el que debe disipar tales dudas. Pero cuando es evidente ya en el momento de la constatación del hecho típico que éste no es antijurídico y, por lo mismo, que no constituye delito, por ejemplo, porque concurre la causa de justificación cumplimiento de un deber, no resulta procedente la detención. De lo contrario, habría que aceptar la absurda conclusión de que un funcionario policial tendría que detener por flagrante delito de secuestro o detención ilegal a otro agente policial a quien sorprenda deteniendo a un carterista en el momento en que éste asalta a su víctima. En otras palabras, para la detención por flagrancia delictiva basta la tipicidad del hecho, aun cuando se alberguen dudas acerca de su antijuridicidad; pero cuando sea obvia la concurrencia de una causa de justificación, la detención no cabe.

Una disquisición similar debería hacerse respecto de los restantes elementos del delito. Constatado un hecho típico, la detención por flagrancia delictiva resulta procedente, aun cuando se tenga dudas acerca de la culpabilidad en su ejecución, como cuando existen antecedentes que sugieren que quien lo ejecutó padecía una privación de razón, o no conocía (o no podía conocer) la ilicitud de su actuar, o no se encontraba en una situación en que le fuera exigible un comportamiento adecuado a Derecho. En todos estos casos, no es la policía, sino el tribunal el encargado de disolver tales dudas. Pero cuando en el momento de la constatación del hecho es evidente que no ha habido culpabilidad en su ejecución $y$, por lo tanto, que no ha constituido un delito, como, por ejemplo, cuando quien lo ha realizado es un niño de pocos años, la detención por flagrancia delictiva no cabe. Por eso se explica que, a diferencia de lo que sucede con los adolescentes -quienes al momento en que se hubiere dado principio de ejecución del delito sean mayores de catorce y menores de dieciocho años (art. $3^{\circ}$ Ley $N^{\circ} 20.084$ ), respecto de quienes la ley reconoce expresamente la posibilidad de que sean detenidos en hipótesis de flagrancia (art. 31 Ley No 20.084), para los menores de catorce años no está prevista esta posibilidad, sino la adopción de ciertas medidas de

necesario que ella abarque la antijuridicidad y la culpabilidad, porque tal análisis va más allá de la exigencia de una mera apariencia de comisión de un delito, y sólo es pertinente para valorar el supuesto material y la necesidad de cautela, en el evento que se solicite otra medida cautelar". 
protección que, en todo caso, igualmente importan una afectación de su libertad ambulatoria (art. 58 Ley N²0.084).

\section{Aspectos De TeOrÍA DEL DELITO EN LA REGUlaCión DE LA PRISIÓN}

\section{PREVENTIVA}

\section{Generalidades sobre fumus delicti commissi en la prisión preventiva}

De acuerdo con lo establecido en el artículo 140 CPP, para que se pueda decretar la prisión preventiva, el solicitante (el Ministerio Público o el querellante) debe acreditar que hay antecedentes que justifiquen la existencia del delito que se investiga [letra a)] y que existen antecedentes $\left(\right.$ los mismos $\mathrm{u}$ otros ${ }^{28}$ ) que permitan presumir fundadamente que el imputado ha tenido participación en el delito como autor, cómplice o encubridor [letra b)]. Esto significa que debe demostrar la existencia de cargos serios, a través de la mención de dichos antecedentes. Para evaluar la seriedad de los antecedentes, el juez debería considerar dos aspectos: uno material, o sea, la cantidad y la calidad de esos antecedentes, y otro legal, es decir, que los antecedentes no hayan sido obtenidos con vulneración de garantías, pues carecería de sentido decretar una medida cautelar fundada en evidencia que probablemente será excluida como prueba en la audiencia de preparación de juicio oral por ilicitud de la misma (art. 276 inc. $\left.3^{\circ} \mathrm{CPP}\right)^{29}$.

No existe claridad acerca del estándar probatorio que se debe alcanzar para estimar cumplido este requisito (antecedentes que justifiquen el delito y que permitan presumir fundadamente la participación) $)^{30}$.

${ }^{28}$ Así, implícitamente, Duce Julio, Mauricio - Riego Ramírez, Cristián, La prisión preventiva en Chile: análisis de los cambios legales y su impacto (Santiago, Ediciones Universidad Diego Portales, 2011), p. 42. En contra, CARocca Pérez, Álex, Manual el nuevo sistema procesal penal chileno (4a edición, Santiago, LegalPublishing, 2008), p. 112, quien parece sugerir que debe tratarse de otros antecedentes.

${ }^{29}$ En este sentido, véase Hernández Basualto, Héctor, La exclusión de la prueba ilícita en el nuevo proceso penal chileno, en Colección de Investigaciones Jurídicas de la Escuela de Derecho de la Universidad Alberto Hurtado 2 (2002), pp. 87-89. Similar, Miranda Estrampes, Manuel - Cerda San Martín, Rodrigo - Hermosilla Iriarte, Francisco, Práctica de la prueba en el juicio oral. Su valoración y el estándar del "más allá de toda duda razonable" (Santiago, Librotecnia, 2012), pp. 302-305. En igual sentido, pero aludiendo a la legislación procesal penal brasileña, Prado, Geraldo, Excepcionalidade da prisão provisória, en Fernandes, Og (coord.), Medidas cautelares no processo penal. Prisóes e suas alternativas (São Paulo, Editora Revista Dos Tribunais, 2011), p. 116.

${ }^{30}$ Sobre el tema, véase Oliver CALderón, Guillermo, Estándar probatorio en los mecanismos chilenos de justicia penal negociada, en Santibáñez Torres, María Elena (dir.) - Marcazzolo Awad, Ximena (coord.), La prueba en los procedimientos. VII 
Algunos sostienen que lo que se requiere es que los antecedentes permitan prever que se llevará adelante un juicio en el que la prueba será examinada detenidamente y valorada en la sentencia, juicio en el que habrá buena probabilidad de obtener una condena ${ }^{31}$. Otros exigen que los antecedentes permitan obtener un elevado grado de convencimiento acerca de la existencia del delito y de la participación del imputado en él $^{32}$. Otros señalan, a partir de la constatación de que al aludir al delito la ley exige que los antecedentes lo justifiquen, en tanto que al referirse a la participación requiere que los antecedentes permitan presumirla fundadamente, que el estándar sería más elevado en lo concerniente al hecho que en lo relativo a la participación ${ }^{33}$.

No es extraño que no exista claridad sobre este punto en la doctrina, porque en estricto rigor, lo que la ley menciona en materia de prisión preventiva es solo aquello que debe demostrarse (el delito y la participación), sin que explicite ningún estándar probatorio que deba alcanzarse, a diferencia de lo que sucede en materia de condena, en la que la ley sí fija un estándar: superación de toda duda razonable (art. 340 CPP). Debería proponerse por la doctrina la adopción de algún estándar para la prisión preventiva, el cual tendría que ser inferior al de la duda razonable, pero superior al de la prueba prevalente o preponderante, por ser este último más bien propio del proceso civil ${ }^{34}$.

Ahora bien, la calificación jurídica de los hechos y de la participación compete al juez y no al Ministerio Público. En la práctica, cuando el fiscal formaliza la investigación y pide medidas cautelares, suele mencionar una determinada calificación jurídica, pero no es ésta la que el juez debe considerar, sino la que estime pertinente de acuerdo con los antecedentes suministrados ${ }^{35}$.

Jornadas Nacionales de Derecho Procesal (Santiago, Thomson Reuters; Pontificia Universidad Católica de Chile, 2019), pp. 539-540.

${ }^{31}$ Así, Duce Julio, Mauricio - Riego Ramírez, Cristián, Proceso Penal (Santiago, Editorial Jurídica de Chile, 2007), p. 252.

${ }^{32}$ Cfr. CASTRO Jofré, Javier, Manual de derecho procesal penal (Santiago, Libromar, 2017), p. 275, poniendo énfasis en el peso de los antecedentes que se invocan.

${ }^{33}$ Así lo señala Julián López Masle en Horvitz Lennon, María Inés - López Masle, Julián, Derecho Procesal Penal Chileno (Santiago, Editorial Jurídica de Chile, 2002), I, p. 401. En el mismo sentido, Maturana - Montero, cit. (n. 13), I, pp. 659-660; CERDA, cit. (n. 17), p. 372.

${ }^{34}$ En esta línea se inserta la proposición de Beltrán Calfurrapa, Ramón, Estándares de prueba y su aplicación sobre el elemento material de la prisión preventiva en Chile, en Politica Criminal 7 (2012), 14, pp. 454-479.

${ }^{35}$ En igual sentido, Falcone Salas, Diego, Apuntes sobre la formalización de la investigación desde la perspectiva del objeto del proceso penal, en Revista de Derecho de la 
Por otra parte, lo que exige el artículo $140 \mathrm{CPP}$ es acreditar que existan antecedentes, por lo que no cabe fundar la solicitud (ni tampoco la resolución que recae sobre ella) en presunciones legales que en el ordenamiento jurídico penal chileno, lamentablemente, aún subsisten. Por ejemplo, no podría el Ministerio Público, simplemente, invocar la presunción de autoría de tentativa de robo del artículo 444 CP si se sorprendiera a una persona ingresando a una casa ajena por la ventana; tendría que acreditar la existencia de antecedentes que desvirtúen la presunción de inocencia que ampara al imputado. En todo caso, claro está, esto no obsta a que el juez pueda fundar su resolución sobre indicios.

\section{Consideraciones de teoría del delito}

Del análisis general del fumus delicti commissi en la regulación de la prisión preventiva se desprende que el más importante aspecto propio de la teoría del delito que se proyecta en aquélla es el mismo que ya se ha analizado a propósito de la detención por flagrancia delictiva: qué es lo que debe entenderse por "delito".

Sin embargo, a diferencia de lo que sucede en materia de detención por flagrancia delictiva, en el ámbito de la prisión preventiva sí se ha estudiado por la doctrina nacional el sentido del vocablo "delito", materia en la cual se ha suscitado una discusión. Para algunos, dicho término debe entenderse solo como una alusión a un hecho típico, sin que interese examinar que éste sea, además, antijurídico y culpable ${ }^{36}$. Otros parecen

Universidad Católica del Norte 21 (2014), 2, p. 202, n. 80. Similar, en relación con el delito de alteración fraudulenta de precios, del artículo 285 CP, WinTER ETCHEBERry, Jaime - Correa Robles, Carlos, Prisión preventiva y delitos empresariales en Chile, en Perspectiva Penal Actual 3 (2014), p. 227.

${ }^{36}$ En este sentido, NúNÉz VÁsQuez, Cristóbal, Tratado del proceso penal y del juicio oral (Santiago, Editorial Jurídica de Chile, 2003), I, p. 304; Del Río Ferretti, Carlos - Rojas Rubilar, Francisco, De la Reforma Procesal Penal. En especial de la etapa de instrucción e intermedia (Santiago, Conosur, 1999), p. 309; Aguilar Aranela, Cristian, Manual de Derecho Procesal Penal Oral (Santiago, Editorial Metropolitana, 2004), I, pp. 245-246, aunque este último autor cambió su postura en Aguilar, cit. (n. 16), pp. 72-73.

Dado que la referencia al fumus delicti commissi para la prisión preventiva en el artículo $140 \mathrm{CPP}$ es prácticamente idéntica a los requisitos que el artículo 274 del antiguo Código de Procedimiento Penal exigía para que el juez del crimen pudiera dictar auto de procesamiento contra el inculpado, es posible que en la opinión expuesta en el texto influyera el parecer de quienes entendían que el vocablo "delito" sólo significaba un hecho típico. Así lo afirmaban, entre otros, Fontecilla Riquelme, Rafael, Tratado de Derecho Procesal Penal (Santiago, Editorial Jurídica de Chile, 1978), II, pp. 171-173; Pfeiffer Richter, Alfredo, Apuntes de Derecho Procesal del profesor Pfeiffer (Santiago, s.l. 1998), VII, pp. 130-131. 
exigir la concurrencia de tipicidad y de antijuridicidad ${ }^{37}$. Para otros, tal vocablo debe ser entendido en un sentido técnico, como una referencia a un hecho que reúna todos los elementos para ser considerado un delito ${ }^{38}$.

También en la doctrina extranjera el punto relativo a cómo debe entenderse el fumus delicti commissi en las regulaciones de diversos Estados sobre prisión preventiva o provisional ha suscitado cierta discusión. Mientras algunos afirman que debe ser concebido solo como un hecho típico ${ }^{39}$, la opinión aparentemente mayoritaria, a veces influida por particularidades de las legislaciones ${ }^{40}$, sostiene que dicho presupuesto de la medida cautelar debe ser entendido como un hecho con todos los elementos necesarios para ser constitutivo de delito ${ }^{41}$.

${ }^{37}$ Así lo sugiere Alarcón Corsi, Humberto, Prisión preventiva, terremoto y saqueos: comentario a las sentencias de la Corte Suprema, en Revista Ius et Praxis 16 (2010), 2, p. 398.

${ }^{38}$ Así lo señala Julián López Masle en Horvitz - López, cit. (n. 33), I, p. 405. En el mismo sentido, Maturana - Montero, cit. (n. 13), I, p. 659; Cerda, cit. (n. 17), I, p. 372; HADWA ISSA, Marcelo, La prisión preventiva y otras medidas cautelares personales, (2a edición, Santiago, Editorial Jurídica de Chile, 2016), pp. 104-105.

${ }^{39}$ En este sentido, Jiménez de Asúa, Luis, Tratado de Derecho Penal (3a edición, Buenos Aires, Editorial Losada, 1965), III, pp. 931-935.

${ }^{40}$ Por ejemplo, en España, la Ley de Enjuiciamiento Criminal declara que "no se adoptará en ningún caso la prisión provisional cuando de las investigaciones practicadas se infiera racionalmente que el hecho no es constitutivo de delito o que el mismo se cometió concurriendo una causa de justificación" (art. 502.4). En todo caso, la falta de alusión a la culpabilidad en esta disposición no ha impedido a un sector de la doctrina de dicho país afirmar que este elemento del delito también debe concurrir para que se pueda imponer la medida cautelar. Véase De la Rosa Cortina, José Miguel, Las medidas cautelares personales en el proceso penal (Barcelona, Bosch, 2015), pp. 76-77. Por su parte, Gimeno Sendra, Vicente, Derecho Procesal Penal, (Madrid, Civitas; Thomson Reuters; Aranzadi 2012), pp. 629-630, considera dicha norma como "absolutamente superflua", ya que, "si el hecho adolece de tipicidad penal, lo procedente será el sobreseimiento libre y si concurre alguna causa de justificación, nunca se ha legitimado la prisión provisional, ya que, a diferencia del procesamiento que requiere 'indicios racionales de criminalidad', la existencia de 'motivos bastantes de responsabilidad penal incorpora el plus de la culpabilidad al de la autoría y desde siempre le ha vedado al Juez que ordene el ingreso en prisión de un procesado sobre el que existe la evidencia acerca de la concurrencia de una causa de exención o de extinción de la responsabilidad penal" (las cursivas en el original). Similar, GuTIÉrREZ DE CABIedes, Pablo, La prisión provisional (Navarra, Thomson; Aranzadi, 2004), p. 129, n. 270.

${ }^{41}$ LlObet Rodríguez, Javier, La prisión preventiva (Limites constitucionales) (San José, Editorial Jurídica Continental, 2010), p. 178: "La afirmación del grado de probabilidad se refiere a que el imputado haya cometido un hecho típico, antijurídico y culpable; por ello la duda acerca de la existencia de circunstancias que harían justificado el hecho o que excluirían la culpabilidad, impediría el dictado de la 
Por su parte, en la jurisprudencia de nuestros tribunales se encuentran algunos pronunciamientos que parecen sugerir que no corresponde decretar la prisión preventiva si se albergan dudas sobre la concurrencia de elementos del delito adicionales a la tipicidad ${ }^{42}$, aunque también se hallan otros que parecen conformarse con la constatación de la tipicidad, a pesar de que existan dudas sobre los restantes elementos del delito ${ }^{43}$.

Según mi opinión, para efectos de la prisión preventiva, el término "delito" debería ser entendido en un sentido técnico, comprensivo de todos sus elementos. Por algo se ha planteado, como lo señalé más arriba, que para imponer tal medida cautelar se requiere una buena probabilidad de que se dicte una condena; difícilmente esto último podrá tener lugar si existen dudas sobre la antijuridicidad o la culpabilidad del hecho. Entender tal vocablo solo como un hecho típico implicaría infringir lo dispuesto en el artículo $5^{\circ} \mathrm{CPP}$, que ordena interpretar restrictivamente las disposiciones que autorizan afectar derechos del imputado. Incluso, me parece que debería exigirse también la punibilidad del delito y los presupuestos procesales de su persecución ${ }^{44}$, porque carecería de sentido que se pudiera imponer la prisión preventiva en un proceso seguido por un hecho que, aunque se acredite, no pueda sancionarse. La definición legal de delito del artículo $1^{\circ} \mathrm{CP}$ sirve de apoyo a esta afirmación, ya que la exigencia allí contenida, de que la acción u omisión voluntaria esté penada por la ley, permite entender incluida no sólo la tipicidad, sino también la punibilidad.

Así las cosas, no resulta procedente imponer la prisión preventiva cuando el tribunal no puede arribar a la convicción (no íntima, sino objetivamente extraíble de los antecedentes invocados por el solicitante de la medida cautelar), en el estándar que se fije por debajo de la

prisión preventiva”. Véase también, en el mismo sentido, Lima, Marcellus Polastri, A tutela cautelar no processo penal (Río de Janeiro, Editora Lumen Juris, 2005), pp. 256-258; LOPES JR., cit. (n. 8), pp. 68-69.

${ }^{42}$ En este sentido, véanse las sentencias de la Corte de Apelaciones de Antofagasta, de 8 de marzo de 2017, en causa rol $\mathrm{N}^{\circ}$ 78-2017, y de la Corte de Apelaciones de Santiago, de 1 de abril de 2017, en causa rol No 1120-2017, y de 11 de mayo de 2012, en causa rol $\mathrm{N}^{\circ} 1276-2012$.

${ }^{43}$ Así, sentencias de la Corte de Apelaciones de Santiago, de 18 de julio de 2019, en causa rol $N^{\circ} 3754-2019$, y de 17 de septiembre de 2016, en causa rol $N^{\circ} 3130$ 2016.

${ }^{44}$ Cfr. Roxin, cit. (n. 5), p. 259, quien, de modo similar, aludiendo al requisito de la prisión preventiva consistente en que exista "sospecha vehemente con respecto a la comisión del hecho punible”, según el $\$ 112$ de la Ordenanza Procesal Penal alemana, exige que "estén presentes todos los presupuestos de la punibilidad y de la perseguibilidad". 
ausencia de dudas razonables, pero por encima del umbral de la prueba preponderante, de la concurrencia de todos los elementos del delito, incluidos la punibilidad y los presupuestos procesales de su persecución. Por ejemplo, no sólo no corresponde decretar la prisión preventiva cuando el hecho típico no se muestra antijurídico y culpablemente ejecutado, sino tampoco cuando beneficia al imputado una causa personal de exclusión de pena (excusa legal absolutoria), cuando el hecho se encuentra prescrito ni cuando para su persecución se necesita una denuncia o querella de la víctima que aún no se presenta.

Podría causar alguna extrañeza el hecho de que para un mismo vocablo (delito) se proponga la adopción de un significado en materia de detención por flagrancia, y otro distinto en materia de prisión preventiva. Sin embargo, tal diferencia puede ser justificada a partir de la distinta situación en que se encuentran quienes son llamados a apreciar la concurrencia de dicho supuesto. La detención por delito flagrante es normalmente practicada por la policía, aunque también podría ser efectuada por cualquier particular (art. 129 incs. $1^{\circ}$ y $2^{\circ} \mathrm{CPP}$ ). Se trata de una actividad realizada por personas que, usualmente, carecen de formación jurídica profesional y disponen de muy poco tiempo para estimar si están frente a un delito o no en un caso concreto. En cambio, la prisión preventiva es impuesta por el juez, persona que ha recibido formación jurídica por varios años, después de un debate en el que oye los planteamientos de todos los intervinientes (art. 142 CPP), lo que le permite discernir, sin el apuro propio de una situación de flagrancia, no solo si se está ante un hecho típico, sino también si se advierte o no la concurrencia de los demás elementos del delito, incluyendo su punibilidad y los presupuestos procesales para su persecución. Esta diferente posición en que se encuentran la policía y el tribunal justifica que el alcance que se atribuya a la locución "delito" en la detención por flagrancia y en la prisión preventiva sea distinto: más exigente en ésta, menos en aquélla.

Abona esta idea el hecho de que, a diferencia de la detención, medida cautelar que implica una privación de libertad de corta duración-como es sabido, el detenido por flagrancia delictiva debe ser llevado a la presencia judicial en un plazo máximo de veinticuatro horas (art. 131 inc. $2^{\circ} \mathrm{CPP}$ ), la prisión preventiva es de duración indefinida y puede prolongarse por mucho tiempo. No existe en la legislación chilena un límite máximo para su duración. Incluso podría extenderse por todo el tiempo de la pena que pudiera esperarse en el caso de condenarse al imputado (art. 152 inc. $2^{\circ}$ $\mathrm{CPP).} \mathrm{Así} \mathrm{las} \mathrm{cosas,} \mathrm{parece} \mathrm{razonable} \mathrm{plantear} \mathrm{mayores} \mathrm{exigencias} \mathrm{para}$ estimar concurrente el fumus delicti commissi en la prisión preventiva que en la detención por flagrancia. 


\section{Conclusiones}

Al finalizar este trabajo, dejo establecidas, a modo de conclusiones, las principales afirmaciones efectuadas a lo largo de su desarrollo:

1. El examen de la regulación de la detención por flagrancia delictiva sugiere que cuando ella usa el vocablo "delito", en general, lo hace para referirse a un hecho que es típico.

2. Para que la policía (o cualquier particular) pueda detener por flagrancia, no es razonable exigirle la comprobación, en el momento de constatación del hecho delictivo, de elementos del delito adicionales a la tipicidad, varios de los cuales podrían permanecer en la incertidumbre hasta la sentencia definitiva. Una investigación policial orientada a esclarecer esos otros elementos del delito es contraria a la idea de flagrancia.

3. Sin embargo, cuando ya en el momento de la constatación del hecho típico es evidente que no es antijurídico, por concurrir una causa de justificación, no resulta procedente la detención por delito flagrante. Del mismo modo, cuando en ese mismo instante es evidente que no ha habido culpabilidad en su ejecución, la detención por flagrancia delictiva no cabe.

4. En la regulación procesal penal sobre prisión preventiva, la referencia al "delito" en la exigencia de fumus delicti commissi debe ser entendida en un sentido técnico, comprensivo de todos sus elementos. Incluso, debería exigirse también la concurrencia de la punibilidad del hecho y los presupuestos procesales de su persecución.

5. Para imponer la prisión preventiva, la convicción del tribunal acerca de la concurrencia de todos los elementos del delito, incluidos la punibilidad y los presupuestos procesales de su persecución, no debe ser íntima, sino objetivamente extraíble de los antecedentes invocados por quien solicita la medida cautelar, y debe alcanzar un estándar que se sitúe por debajo de la ausencia de dudas razonables, pero por encima del umbral de la prueba preponderante.

6. La atribución a un mismo vocablo (delito) de un significado en materia de detención por flagrancia y otro diferente en materia de prisión preventiva, puede ser justificada a partir de la distinta situación en que se hallan quienes son llamados a apreciar la concurrencia de dicho supuesto. La diferente posición en que se encuentran la policía y el tribunal explica que el alcance de dicha locución sea más exigente para la prisión preventiva que para la detención por flagrancia.

7. Esta mayor exigencia para apreciar el fumus delicti commissi en la prisión preventiva que en la detención por flagrancia, puede ser justificada también por el hecho de que, a diferencia de la detención, que implica 
una privación de libertad de corta duración, la prisión preventiva puede prolongarse por mucho tiempo.

\section{BibLIOGRAFÍA}

Aguilar Aranela, Cristian, Medidas cautelares personales y reales en el proceso penal (Santiago, Librotecnia, 2014).

Aguilar Aranela, Cristian, Manual de Derecho Procesal Penal Oral (Santiago, Editorial Metropolitana, 2004), I.

Alarcón Corsi, Humberto, Prisión preventiva, terremoto y saqueos: comentario a las sentencias de la Corte Suprema, en Revista Ius et Praxis 16 (2010), 2.

Beltrán Calfurrapa, Ramón, Estándares de prueba y su aplicación sobre el elemento material de la prisión preventiva en Chile, en Politica Criminal 7 (2012), 14.

Carocca Pérez, Álex, Manual el nuevo sistema procesal penal chileno (4ª edición, Santiago, LegalPublishing, 2008).

CASTro Jofré, Javier, Manual de derecho procesal penal (Santiago, Libromar, 2017).

Cerda San Martín, Rodrigo, Segunda Ley de Agenda Corta Antidelincuencia. Comentarios desde la práctica jurisdiccional (Santiago, Librotecnia, 2016).

Cerda SAn Martín, Rodrigo, Manual del sistema de justicia penal (2a edición, Santiago, Librotecnia, 2010), I.

Cerezo Mir, José, Derecho Penal. Parte General (Buenos Aires-Montevideo, B de F, 2008).

Cisterna Pino, Adolfo, La detención por flagrancia en el nuevo proceso penal. Doctrina y jurisprudencia (Santiago, Librotecnia, 2004).

De Hoyos Sancho, Montserrat, La detención por delito (Pamplona, Aranzadi, 1998).

De la Rosa Cortina, José Miguel, Las medidas cautelares personales en el proceso penal (Barcelona, Bosch, 2015).

Del Río Ferretti, Carlos - Rojas Rubilar, Francisco, De la Reforma Procesal Penal. En especial de la etapa de instrucción e intermedia (Santiago, Conosur, 1999).

Duce Julio, Mauricio - Riego Ramírez, Cristián, La prisión preventiva en Chile: análisis de los cambios legales y su impacto (Santiago, Ediciones Universidad Diego Portales, 2011).

Duce Julio, Mauricio - Riego Ramírez, Cristián, Proceso Penal (Santiago, Editorial Jurídica de Chile, 2007).

Durán FuiCA, Rodrigo, Medidas cautelares personales en el proceso penal (3a edición, Santiago, Librotecnia, 2011).

FalCONE SALAS, Diego, Apuntes sobre la formalización de la investigación desde la perspectiva del objeto del proceso penal, en Revista de Derecho de la Universidad Católica del Norte 21 (2014), 2.

Falcone Salas, Diego, Concepto y sistematización de la detención ilegal en el proceso penal chileno, en Revista de Derecho de la Pontificia Universidad Católica de Valparaíso 38 (2012).

Fontecilla RiQuelme, Rafael, Tratado de Derecho Procesal Penal (Santiago, Editorial Jurídica de Chile, 1978).

FREUND, Georg, Sobre la función legitimadora de la idea de fin en el sistema integral del Derecho penal, en Wolter, Jürgen - Freund, Georg (eds.), El sistema integral del Derecho penal. Delito, determinación de la pena y proceso penal (Madrid, Marcial Pons, 2004). 
Gimeno Sendra, Vicente, Derecho Procesal Penal (Madrid, Civitas; Thomson Reuters; Aranzadi, 2012).

Gutiérrez de Cabiedes, Pablo, La prisión provisional (Navarra, Thomson; Aranzadi, 2004).

HadWA IsSA, Marcelo, La prisión preventiva y otras medidas cautelares personales (2a edición, Santiago, Editorial Jurídica de Chile, 2016).

Hernández Basualto, Héctor, La exclusión de la prueba ilícita en el nuevo proceso penal chileno, en Colección de Investigaciones Jurídicas de la Escuela de Derecho de la Universidad Alberto Hurtado 2 (2002).

Horvitz Lennon, María Inés - López Masle, Julián, Derecho Procesal Penal Chileno (Santiago, Editorial Jurídica de Chile, 2002), I.

Jakoвs, Günther, Derecho Penal. Parte General. Fundamentos y teoría de la imputación (traducción de la 2a edición alemana de Joaquín Cuello Contreras y José Luis Serrano González de Murillo, Barcelona, Marcial Pons, 1997).

Jiménez de Asúa, Luis, Tratado de Derecho Penal (3a edición, Buenos Aires, Editorial Losada, 1965), III.

Lima, Marcellus Polastri, A tutela cautelar no processo penal (Río de Janeiro, Editora Lumen Juris, 2005).

Llobet RodrígueZ, Javier, La prisión preventiva (Limites constitucionales) (San José, Editorial Jurídica Continental, 2010).

LOPES JR., Aury, O novo regime jurídico da prisão processual, liberdade provisória e medidas cautelares diversas (Río de Janeiro, Editora Lumen Juris, 2011).

Maier, Julio B. J., Derecho Procesal Penal (Buenos Aires, Ad-Hoc, 2016).

Marín GonzÁlez, Juan Carlos, Las medidas cautelares personales en el nuevo Código Procesal Penal chileno, en Revista de Estudios de la Justicia 1 (2002).

Maturana Miquel, Cristián - Montero López, Raúl, Derecho Procesal Penal (3a edición, Librotecnia, Santiago, 2017), I.

Mir Puig, Santiago, Derecho Penal. Parte General (10 edición, Barcelona, Reppertor, 2016).

Miranda Estrampes, Manuel - Cerda San Martín, Rodrigo - Hermosilla Iriarte, Francisco, Práctica de la prueba en el juicio oral. Su valoración y el estándar del "más allá de toda duda razonable" (Santiago, Librotecnia, 2012).

Nieva Fenoll, Jordi, Derecho Procesal III. Proceso penal (Madrid, Marcial Pons, 2017)

Nieva Fenoll, Jordi, Fundamentos de Derecho Procesal Penal (Madrid, Buenos Aires, Montevideo, Edisofer; B de F, 2012).

NúŃEz VÁsquez, Cristóbal, Tratado del proceso penal y del juicio oral (Santiago, Editorial Jurídica de Chile, 2003).

Oliver Calderón, Guillermo, Estándar probatorio en los mecanismos chilenos de justicia penal negociada, en Santibáñez Torres, María Elena (dir.), Marcazzolo AwAD, Ximena (coord.), La prueba en los procedimientos. VII Jornadas Nacionales de Derecho Procesal (Santiago, Thomson Reuters; Pontificia Universidad Católica de Chile, 2019).

Oliver Calderón, Guillermo, Facultades autónomas de la policía en el sistema procesal penal chileno, en Revista de Derecho de la Pontificia Universidad Católica de Valparaiso 51 (2018).

PASTOR, Daniel R., Acerca de presupuestos e impedimentos procesales y sus tendencias actuales (2001), ahora, en ÉL MISMO, Tensiones. ¿Derechos fundamentales o persecución penal sin límites? (Buenos Aires, Editores del Puerto, 2004). 
Pfeiffer Richter, Alfredo, Apuntes de Derecho Procesal del profesor Pfeiffer (Santiago, s.l. 1998), VII.

Prado, Geraldo, Excepcionalidade da prisão provisória, ahora, en Fernandes, Og (coord.), Medidas cautelares no processo penal. Prisóes e suas alternativas (São Paulo, Editora Revista Dos Tribunais, 2011).

Pujadas Tortosa, Virginia, Teoría general de medidas cautelares penales. Peligrosidad del imputado y protección del proceso (Madrid, Marcial Pons, 2008).

QUERALT JIMÉNEZ, Joan, La detención preprocesal preventiva: previsiones constitucionales y legales, ahora, en Álvarez Álvarez, Gregorio (dir.), Detención policialy "babeas corpus" (Madrid, Consejo General del Poder Judicial, 2010).

RAGUÉS I VALlès, Ramon, Derecho penal sustantivo y Derecho procesal penal: hacia una visión integrada, en Hurtado Pozo, José (dir.), Anuario de Derecho Penal. La reforma del proceso penal peruano (Lima, PUCP, Fondo editorial-Universidad de Friburgo Suiza, 2004).

Romero Muza, Rubén, Control de identidady detención. Doctrina y jurisprudencia (2a edición, Librotecnia, Santiago, 2007).

Roxin, Claus, Derecho Procesal Penal (traducción de la 25a edición alemana de Gabriela E. Córdoba y Daniel R. Pastor, Buenos Aires, Editores del Puerto, 2000).

SÁnchez Rodríguez, Sergio, Para entender la agenda corta antidelincuencia. Ley 20.931 (Santiago, Editorial Metropolitana, 2016).

Vera SÁnchez, Juan Sebastián, Sobre la relación del Derecho penal con el Derecho procesal penal, en Revista Chilena de Derecho 44 (2017), 3.

VitAR CÁCERES, Jorge, La detención por flagrancia y la modificación de la Ley 20.253, en Fuentes Maureira, Claudio (coord.), Diez años de la reforma procesal penal en Chile (Santiago, Ediciones Universidad Diego Portales, 2011).

Winter Etcheberry, Jaime - Correa Robles, Carlos, Prisión preventiva y delitos empresariales en Chile, en Perspectiva Penal Actual 3 (2014).

Zaffaroni, Eugenio Raúl - Alagia, Alejandro - Slokar, Alejandro, Derecho Penal. Parte General (2a edición, Ediar, Buenos Aires, 2003). 